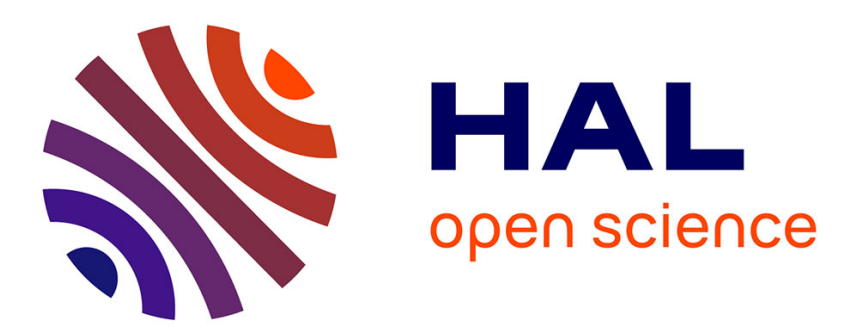

\title{
Characteristics of PDT performed very shortly after sensitizer injection
}

L. Bourletias, P. Lenz, J. Margonari

\section{To cite this version:}

L. Bourletias, P. Lenz, J. Margonari. Characteristics of PDT performed very shortly after sensitizer injection. Journal de Physique IV Proceedings, 1994, 04 (C4), pp.C4-241-C4-244. 10.1051/jp4:1994455 . jpa-00252718

\section{HAL Id: jpa-00252718 https://hal.science/jpa-00252718}

Submitted on 1 Jan 1994

HAL is a multi-disciplinary open access archive for the deposit and dissemination of scientific research documents, whether they are published or not. The documents may come from teaching and research institutions in France or abroad, or from public or private research centers.
L'archive ouverte pluridisciplinaire HAL, est destinée au dépôt et à la diffusion de documents scientifiques de niveau recherche, publiés ou non, émanant des établissements d'enseignement et de recherche français ou étrangers, des laboratoires publics ou privés. 


\title{
Characteristics of PDT performed very shortly after sensitizer injection
}

\author{
L. BOURLETLAS, P. LENZ and J. MARGONARI
}

INSERM U. 281, 69424 Lyon, France

\begin{abstract}
Clinical PDT is done a few days after injection of the photosensitizer in order to enhance specificity. In animal experiments, however, a strong response is often the principal goal; this is expected to occur if the time delay between injection and irradiation (td) is short. We have defined criteria to assess the strength of photodynamic lesions produced in healthy tissue (rat ears) and examined its dependence on td and on dose fractionation. It is found that, starting from the shortest experimentally accessible value of $t d(10 \mathrm{~min})$, the lesion decreases monotonously and that split light delivery (two portions separated by a $7 \mathrm{~min}$ interval) enhances the lesion.
\end{abstract}

Introduction

In clinical PDT a tumor is irradiated two or three days after the injection of the photosensitizer because at that time the photosensitizer concentration ratio between tumor and surrounding tissue is believed to be at a maximum. The absolute concentration, however, reaches its maximum much earlier. Therefore, if a strong photodynamic response is the principal goal rather than specificity, as in many animal experiments, the time delay between injection and irradiation (td) must be short. This study strives to determine the intensity of photodynamic lesions as a function of td for low values of this parameter and to assess the influence of light fractionation which is expected to further enhance the response but has never been carried out after short delays.

Materials and methods

The experiments are done with healthy tissue since no tumor-specific effect is involved. Rat ears have proven to be a very convenient target due to their ease of access, not only during irradiation but in particular during long term observation. The rats are given $20 \mathrm{mg} / \mathrm{kg}$ of hematoporphyrin derivative by injection into the femoral vein. Each ear is irradiated in two spots distant of 7 
$\mathrm{mm}$, one before and the other behind what could be called the symmetry axis of the ear. Of course it would be advantageous to irradiate more than four spots per animal, but it has been found that a rather large distance between spots is required to avoid interference. A Xenon lamp is used as light source the arc of which is imaged through filters onto a hole of $2.2 \mathrm{~mm}$ diameter. The rat ears are attached to a frame and placed in front of this hole, between two thin glass plates and some glycerol. Each spot receives the same light dose (about $70 \mathrm{~mW}$ during $7 \mathrm{~min}$ ) in a wavelength band reaching from $510 \mathrm{~nm}$ to $570 \mathrm{~nm}$. This rather high dose is necessary to produce convenient lesions.

Fig. 1

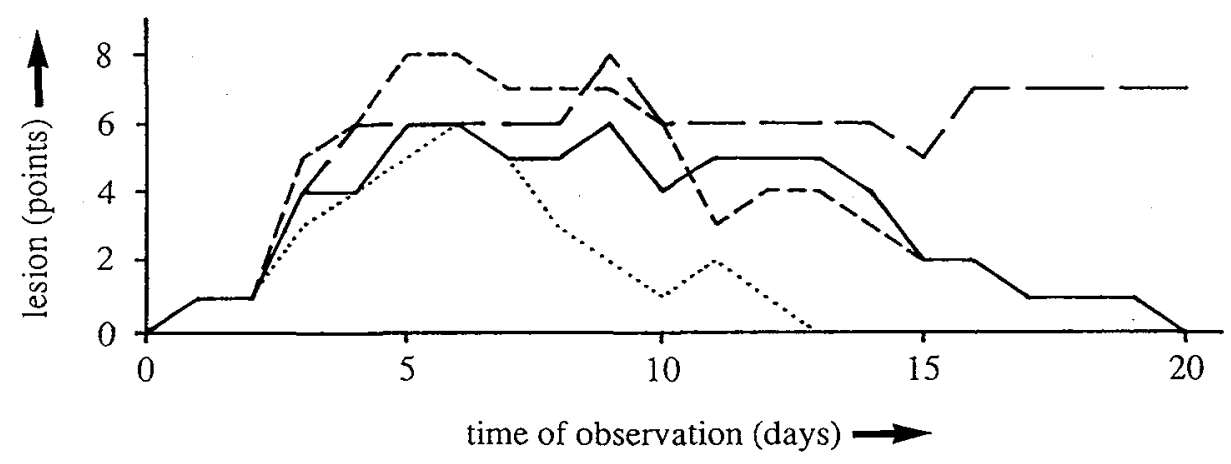

In order to quantify the intensity of photodynamic lesions a method has been set up which is based on the assessment of the time-dependent visual appearance of the lesions. Although results depend on td and on individual peculiarities of the animals, the typical development of a photodynamic lesion of a rat ear can be summarized as follows: After the formation of a slight diffuse erythema the entire ear becomes more or less white-bluish. Then the signs of injury are concentrated in the irradiated spots. These are first white, then yellow, until a scab forms. From this stage on two alternative kinds of evolution are observed. Either there is a hole or the scab falls off, leaving a red spot; this is the sign of a healing process. Besides this principal line other effects are sometimes observed which are not related to a particular stage. For instance the thickness of the ear may be locally diminished or the lesion may fan out towards the border of the ear, undoubtedly as a consequence of impaired blood circulation. The ensemble of these penomena is attributed a system of points which takes also into account the surface covered by the lesion. Although this system is defined 
arbitrarily it leads to reasonably smooth curves. Fig.1 gives an example of a rat which produced one quickly healing lesion, one perforation and two intermediate cases. It is seen that a daily observation during 20 days is sufficient to give a good idea of the behavior of the lesions and in particular to make perforations evident.

To obtain a time-independent characterization of a lesion the surface below the curve is taken between 0 and 20 days and referred to as the global lesion ( $\mathrm{gl}$ ).

Each rat allows one to draw a curve $\mathrm{gl}(\mathrm{td})$ defined by four points corresponding to four spots of irradiation. The mean and the standard deviation of twenty such curves is represented in fig. 2 :

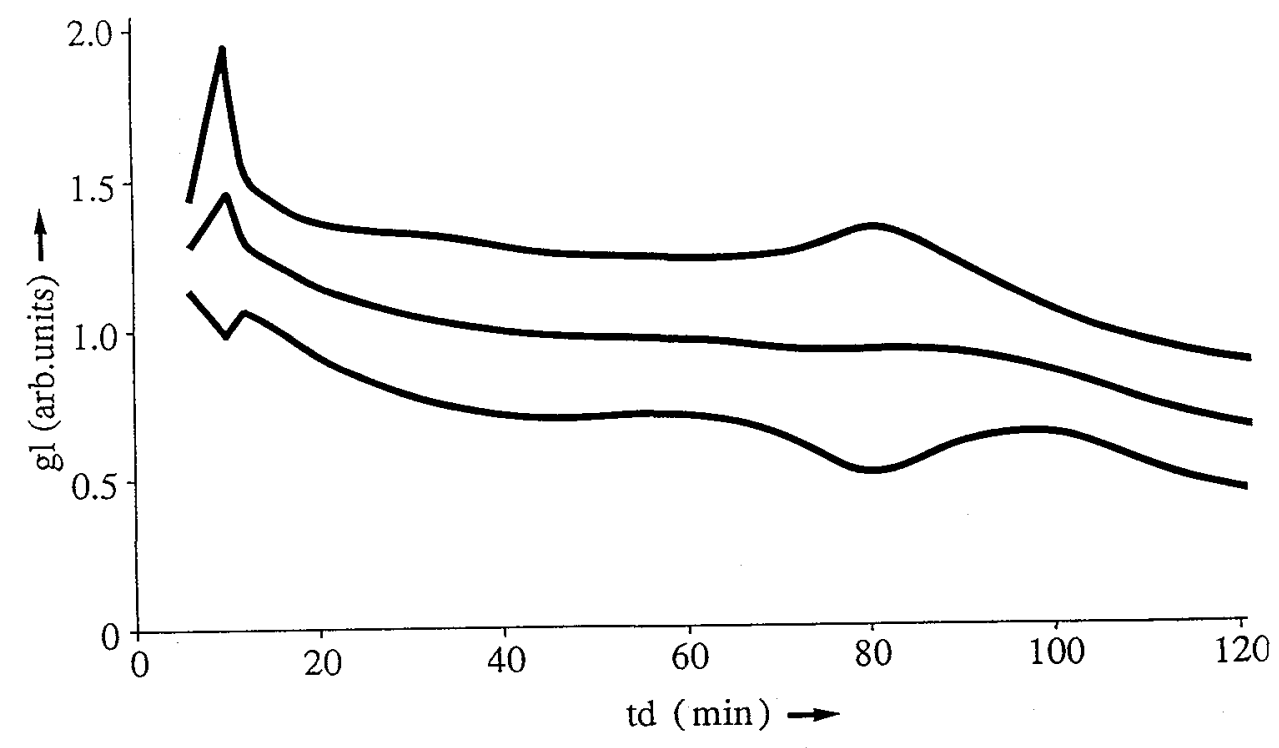

Experiments on light fractionation are carried out with twenty rats. The irradiation is done in two parts of $3.5 \mathrm{~min}$ each, separated by a pause of $7 \mathrm{~min}$, at three different times $t$. The fourth available spot always receives a unique irradiation and serves as a reference. In this way the influence of individual variations of response should be attenuated. The results are also corrected for the decrease of response with time, according to fig. 2 . The normalized means and standard deviations and the irradiation scheme are shown in fig. 3 : 


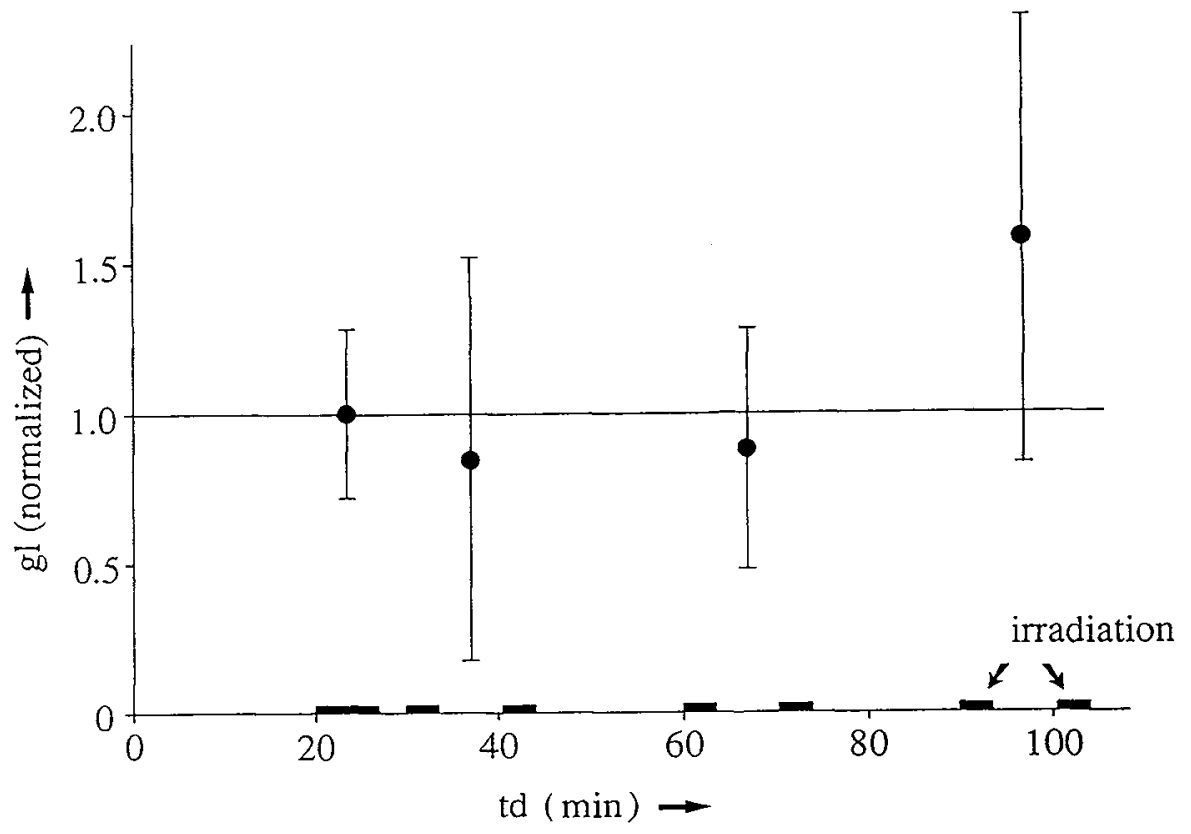

Results

In spite of the effort to take advantage of all observable parameters in the characterization of a lesion the reproducibility of results remains quite bad, as shown by the values of the standard deviations. As a consequence the peak found in fig. 2 for $t d=10$ min has to be interpreted as a statistical fluctuation rather than a sign of maximal photodynamic response. Nevertheless the figure strongly suggests that the maximum occurs a few minutes after injection, followed by a slow decrease. Light fractionation at $t d=37 \mathrm{~min}$ and $67 \mathrm{~min}$ does not seem to have any effect, at $97 \mathrm{~min}$ however there is a distinct enhancement of response with respect to the non fractionated irradiation $(\mathrm{p}<0.001)$. 